\title{
$10 \mathrm{~Gb} / \mathrm{s}-\mathrm{NRZ}$ Optical 2R-regeneration in two-section SOA-EA chip
}

Vivero, Tania; Calabretta, Nicola; Tafur Monroy, Idelfonso; Kassar, G.C.; Öhman, Filip; Yvind, Kresten; Gonzales-Marco, A.; Mørk, Jesper

Published in:

The 20th Annual Meeting of the IEEE Lasers and Electro-Optics Society, 2007. LEOS 2007.

Link to article, DOI:

10.1109/LEOS.2007.4382653

Publication date:

2007

Document Version

Publisher's PDF, also known as Version of record

Link back to DTU Orbit

Citation (APA):

Vivero, T., Calabretta, N., Tafur Monroy, I., Kassar, G. C., Öhman, F., Yvind, K., Gonzales-Marco, A., \& Mørk, J. (2007). $10 \mathrm{~Gb} / \mathrm{s}$-NRZ Optical 2R-regeneration in two-section SOA-EA chip. In The 20th Annual Meeting of the IEEE Lasers and Electro-Optics Society, 2007. LEOS 2007. (pp. ThP2). IEEE. https://doi.org/10.1109/LEOS.2007.4382653

\section{General rights}

Copyright and moral rights for the publications made accessible in the public portal are retained by the authors and/or other copyright owners and it is a condition of accessing publications that users recognise and abide by the legal requirements associated with these rights.

- Users may download and print one copy of any publication from the public portal for the purpose of private study or research.

- You may not further distribute the material or use it for any profit-making activity or commercial gain

- You may freely distribute the URL identifying the publication in the public portal 


\title{
$10 \mathrm{~Gb} / \mathrm{s}-\mathrm{NRZ}$ Optical 2R-Regeneration in Two-Section SOA-EA Chip
}

\author{
Tania Vivero (1,2), Nicola Calabretta (1), Idelfonso Tafur Monroy (1), Gloria Carvalho
} Kassar (1,3), Filip Öhman (1), Kresten Yvind (1), Ana González-Marcos (2) and Jesper Mørk (1).

1) Research Center COM, Tech. Univ. of Denmark, build. 345V.,DK-2800 Kgs. Lyngby, Denmark.

2) E.T.S.I. Telecomunicación, Universidad Politécnica de Madrid, Ciudad Universitaria s/n, 28040-Madrid, Spain.

3) Dipartimento di Elettronica, Politecnico di Torino, Duca degli Abruzi 24-Torino, Italy. (tania.vivero@tfo.upm.es)

\begin{abstract}
All optical 2R-regeneration based on the integration of semiconductor optical amplifiers and electroabsorbers in a single waveguide is experimentally demonstrated. Static transfer functions of concatenated structures show strong improvements of the nonlinearity. An extinction ratio improvement $>4.5 \mathrm{~dB}$ has been obtained under dynamics operation. For optical signalto-noise ratio values above $17 \mathrm{~dB}$, improvement in BER is observed. A receiver sensitivity improvement $>2 \mathrm{~dB}$ at BER of $10^{-9}$ was found for $10 \mathrm{~Gb} / \mathrm{s}$ operation.
\end{abstract}

\section{INTRODUCTION}

All-optical signal processing may play an important role in future high speed communications networks. Signals propagating over fiber networks are distorted due to effects such as attenuation, dispersion, noise and crosstalk and may therefore require regeneration. The benefits of optical regeneration are the potential to increase the transmission length and bit rate. The simplest kind of regeneration includes reamplification and reshaping of the signal, also known as $2 \mathrm{R}$ regeneration. 2R-regeneration has been demonstrated using a Michelson interferometer at $40 \mathrm{~Gb} / \mathrm{s}$ [1], using interferometers with semiconductor optical amplifiers (SOA) in the arms of the interferometers [2] and also using nonlinear effects like cross phase modulation (XPM) or cross gain modulation (XGM) to perform regeneration [3]. Previous solutions $[1,3]$ do not realize a step-like transfer function. However using the structure suggested here, combining concatenated SOA-EA (electroabsorber) sections, we may approach a step-like transfer function. In this paper, we present characterization of the SOA-EA 2R-regenerator device in terms of signal reshaping, extinction ratio (ER) enhancement, bit error rate (BER) measurements and optical signal-to-noise ratio (OSNR) reduction.

\section{PRINCIPLE OF OPERATION}

The regenerator consists of an SOA followed by an EA [4] implemented as a waveguide device on the same semiconductor chip. The operation principle is illustrated in Fig. 1. The SOA displays a gain that is constant up to certain input power, after which it levels off (the output power does not become constant, but approaches a slope of one), as shown by the red line. This reduced output power results in a reduction of amplitude variations at high input levels, corresponding to the logical one-level in an intensity modulated signal. For the EA the absorption is high at low input powers and lower at high input power, as shown by the blue line.
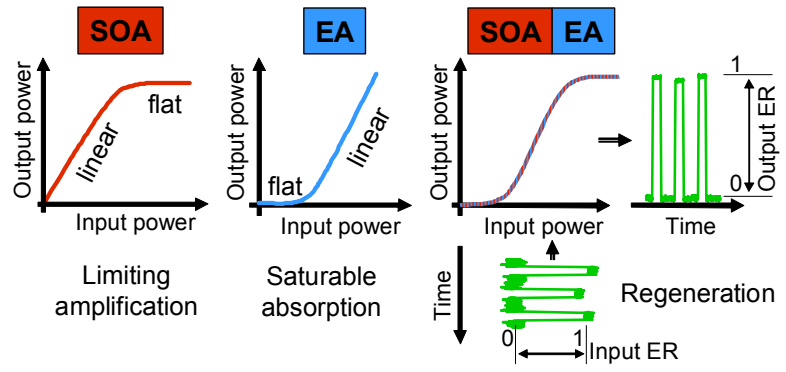

Fig. 1. Schematic SOA-EA regenerator device.

The combination of the SOA and the EA leads to a nonlinear transfer function which increases the separation of the zero and the one level while lowering the fluctuations of each of these. By combining more SOA-EA sections the effect can be enhanced, leading to a steeper transfer function with better characteristics. Fig. 2 (a) shows experimental results for a waveguide containing an SOA and an EA section. The wavelength used is $1520 \mathrm{~nm}$, SOA injection current is 100 $\mathrm{mA}$ and the EA reverse bias voltage is $-0.05 \mathrm{~V}$. Cascading two pairs will enhance the transfer function, as shown in Fig. 2 (b), where it can be clearly seen the great improvement of using another SOA-EA pair. The wavelength used is $1540 \mathrm{~nm}$ and SOAs injection currents are $150 \mathrm{~mA}$ and $175 \mathrm{~mA}$, respectively. EAs reverse bias voltages are $-0.05 \mathrm{~V}$ and -2.25 $\mathrm{V}$, respectively.
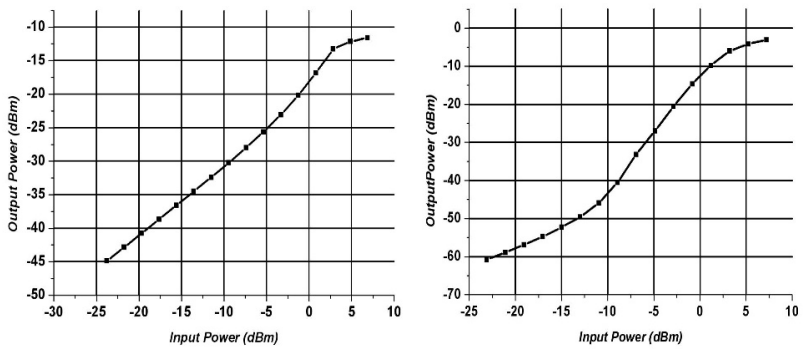

Fig. 2 (a) Measured static power transfer function for one pair of SOA-EA (b) Measured static power transfer function for two pairs of SOA-EA.

\section{EXPERIMENTAL RESULS}

The experimental setup used for dynamic measurements is shown in Fig. 3. The beam of a laser emitting at $1540 \mathrm{~nm}$ is modulated by an intensity modulator driven by an NRZ signal with $2^{31}-1$ PBRS length at the bit rate of $10 \mathrm{~Gb} / \mathrm{s}$. The optical signal is amplified by an erbium doped fiber amplifier (EDFA) and filtered by a band pass filter (BPF) to reduce the amplified spontaneous emission (ASE) noise. The attenuator 
controls the input power level. A polarization controller is used to control the signal polarization at the SOA-EA regenerator input. The length of the SOA and EA sections are $545 \mu \mathrm{m}$ and $120 \mu \mathrm{m}$, respectively. The waveguide is angled $7^{\circ}$ relative to the facets, which are anti-reflection coated to reduce reflections back into the waveguide. The active material consists of five $7.0 \mathrm{~nm}$ thick compressively strained InGaAsP quantum wells in a strain compensated structure. The signal at the regenerator output was filtered by a BPF of $0.8 \mathrm{~nm}$ to reduce the ASE of the $2 \mathrm{R}$. The output signal is controlled by an optical attenuator before being received and processed for BER measurement. The ER of the input data signal is controlled by changing the external modulator bias voltage. The average optical power of the signal at the input of the $2 \mathrm{R}$ is $10.2 \mathrm{dBm}$.

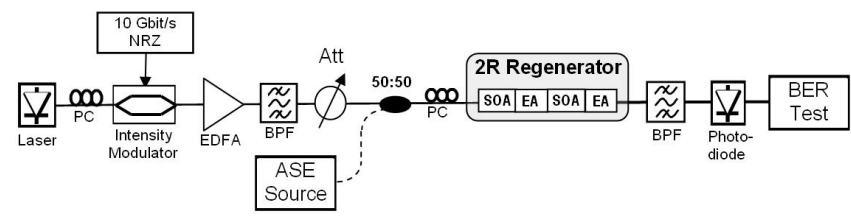

Fig. 3. Experimental setup.

Fig. 4 (a) and Fig 4 (b), shows the eye diagrams and BER measurements at different ER inputs. For an input signal with $3.87 \mathrm{~dB}$ ER, a $4.5 \mathrm{~dB}$ improvement in ER is obtained and with an input signal of $6.79 \mathrm{~dB}$ ER, an ER improvement of $5 \mathrm{~dB}$ is achieved. BER analysis, reported in Fig. 4 (a) and Fig. 4 (b) confirmed the regenerative properties of two pairs of SOA-EA. It is shown that a receiver-sensitivity improvement of $4 \mathrm{~dB}$ at a BER of $10^{-9}$ in the case of signal with $\mathrm{ER}=3.87$ $\mathrm{dB}$, while for $\mathrm{ER}=6.79 \mathrm{~dB}$ an improvement of $2 \mathrm{~dB}$ is achieved. With these results a BER improvement in a cascade regenerator [5] is demonstrated. (a)

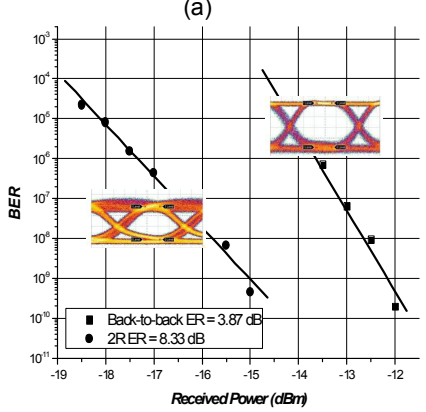

(b)

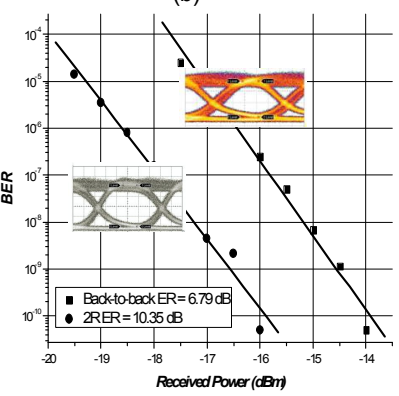

Fig. 4. (a) Eye diagrams and BER measurement results. Input ER: $3.87 \mathrm{~dB}$. Output ER: $8.33 \mathrm{~dB}$ (b) Input ER: $6.79 \mathrm{~dB}$ Output ER: $10.35 \mathrm{~dB}$

OSNR measurements results are given in Fig. 5. In this case the ER of the input signal is around $12 \mathrm{~dB}$. BER curves as a function of the voltage threshold in Fig. 5 (a) show that an OSNR of $20 \mathrm{~dB}$ can be obtained for an input OSNR of $17 \mathrm{~dB}$ and in Fig. 5 (b), an OSNR improvement of $23 \mathrm{~dB}$ can be achieved for input OSNR of $20 \mathrm{~dB}$. Clearly, noise suppression is observed.
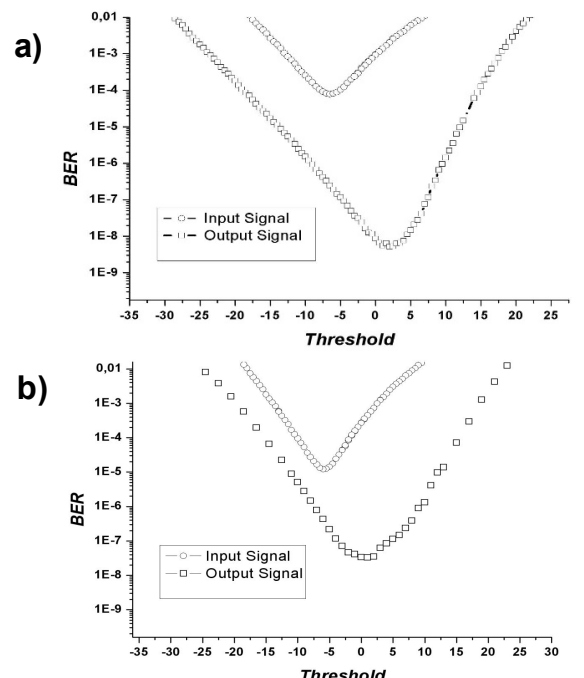

Fig. 5. (a) OSNR input $17 \mathrm{~dB}$ and OSRN output $20 \mathrm{~dB}$ (b) OSNR input 20 $\mathrm{dB}$ and OSNR output $23 \mathrm{~dB}$

\section{CONCLUSIONS}

We have shown experimentally that a two pair SOA-EA regenerator device presents an improved nonlinear response of the typical step-like transfer function. Our $2 \mathrm{R}$ regenerator achieves, depending on the input ER, up to $5 \mathrm{~dB}$ of ER enhancements, and more than $2 \mathrm{~dB}$ of receiver sensitivity improvement at a BER $10^{-9}$ for $10 \mathrm{~Gb} / \mathrm{s}$.

We also analyzed the noise suppression property of this device, recording compression both on the low and high level of the NRZ signal. This demonstrates the effectiveness of the device and the potential use as in-line regenerator in optical transmission system. Finally, we note that the device potentially requires low input power and allows integration with additional optical functions in more complex photonic circuits.

\section{ACKNOWLEDGMENT}

This work was supported by the grant program TIC200304309 of the Ministerio de Educación y Ciencia (MEC) of Spain. The SOA-EA chip was fabricated by Kresten Yvind from the Technical University of Denmark (COM-DTU).

\section{REFERENCES}

[1] D. Wolfson, P. Hansen, A. Kloch, T. Fjelde, C. Janz, A. Coquelin, I Guillemot, F. Gaborit, F. Poingt, and M. Renaud, All-optical 2R regenerationat $40 \mathrm{Gbit} / \mathrm{s}$ in an SOA-based Mach-Zehnder interferometer, in Tech. Dig. OFC, San Diego, CA, 1999, PD 36.

[2] J. De Merlier et al., Experimental Demostration of All-Optical Regeneration Using an MMI-SOA , IEEE Photon. Technol. Lett, vol. 14, pp. 660-662, May 2002.

[3] K. Stubkjaer, Semiconductor Optical Amplifier-Based All-Optical Gates for High-Speed Optical Processing”, IEEE Journal on Selected Topics in Quantum Electronics, vol. 6 pp.1428-1435, 2000.

[4] L.J. Christiansen, L. Xu, K. Yvind, F. Ohman, L. Oxenlowe, J. Mork. $2 \mathrm{R}$ regeneration in concatenated semiconductor optical amplifiers and electroabsorbers . ECOC 2004, Stockholm, Sweden, 2004, Mo3.4.3.

[5] F. Ohman, J. Mork. Modeling of Bit Error Rate in Cascaded 2R Regenerators . J. Lightw. Technol. vol. 24, no. 2, pp.1057-1063, 2006.

[6] F. Öhman, R. Kjær, L.J. Christiansen, K. Yvind and J. Mørk. Steep and Adjustable Transfer Functions of Monolithic SOA-EA 2RRegenerators . IEEE Photon. Technol. Lett. 18, 1067-1069, 2006. 